JOURNAL OF GEOPHYSICAL RESEARCH, VOL. 86, NO. A2, PAGES 609-621, FEBRUARY 1, 1981

\title{
A THEORETICAL STUDY OF THE HIGH-LATITUDE WINTER F REGION AT SOLAR MINIMUM FOR LOW MAGNETIC ACTIVITY
}

\author{
J. J. Sojka, W. J. Raitt, and R. W. Schunk
}

Center for Atmospheric and Space Sciences, Utah State University, Logan, Utah 84322

\begin{abstract}
We combined a simple plasma convection model with an ionospheric-atmospheric composition model in order to with an the high-latitude winter $\mathrm{F}$ region at solar minimum for low magnetic activity. Our numerical study produced time dependent, three-dimensional ion density distributions for the ions $\mathrm{NO}^{+}, \mathrm{O}_{2}^{+}, \mathrm{N}_{2}^{+}, \mathrm{O}^{+}, \mathrm{N}^{+}$, and $\mathrm{He}^{+}$. We covered the highlatitude ionosphere above $54^{\circ} \mathrm{N}$ magnetic latitude and at altitudes between 160 and $800 \mathrm{~km}$ for a time period of one complete day. The main result we obtained was that high-latitude ionospheric features, such as the 'main trough,' the 'ionization hole,' the 'tongue of ionization,' the 'aurorally produced ionization peaks,' and the 'universal time effects,' are a natural consequence of the competition between the various chemical and transport processes known to be operating in the high-latitude ionosphere. In addition, we found that (1) the F region peak electron density at a given location and local time can vary by more than an order of magnitude, owing to the UT effect that results from the displacement between the geomagnetic and geographic poles; (2) a wide range of ion compositions can occur in the polar F region at different locations and times; (3) the minimum value for the electron density in the main trough is sensitive to nocturnal maintenance processes; (4) the depth and longitudinal extent of the main trough exhibit a significant UT dependence; (5) the way the auroral oval is positioned relative to the plasma convection pattern has an appreciable effect on the magnetic local time extent of the main trough; (6) the spatial extent, depth, and location of the polar ionization hole are UT dependent; (7) the level of ion production in the morning sector of the auroral oval has an appreciable effect on the location and spatial extent of the polar ionization hole; and (8) in the polar hole the $\mathrm{F}$ region peak electron density is below $300 \mathrm{~km}$, and at $300 \mathrm{~km}$, diffusion is a very important process for both $\mathrm{O}^{+}$and $\mathrm{NO}^{+}$. Contrary to the suggestion based on an analysis of AE-C satellite data obtained in the polar hole that the concentration of $\mathrm{NO}^{+}$ions is chemically controlled, we find diffusion to be the dominant process at $300 \mathrm{~km}$.
\end{abstract}

\section{Introduction}

Over the last several years we developed a theoretical model of the convecting high-latitude ionosphere in order to determine the extent to which various chemical and transport processes affect the ion composition and electron density in both the sunlit and dark hemispheres ]Banks et al., 1974; Schunk and Banks, 1975; Schunk et al., 1975, 1976; Schunk and Raitt, 1980]. From these studies, as well as those by Knudsen ]1974], Knudsen et al. ]1977], Spiro et al. ]1978], Watkins ]1978], and Brinton et al. [1978], it is apparent that the high-latitude ionosphere can, by varying degrees, be influenced by solar EUV radiation, energetic particle precipitation, diffusion, thermospheric winds, electrodynamic drifts, polar wind escape, energy dependent chemical reactions, and magnetic storm induced neutral composition changes.

In our most recent study [Schunk and Raitt, 1980], we improved our high-latitude ionospheric-atmospheric model so that we could study the solar cycle, seasonal, and geomagnetic activity variations of the daytime high-latitude F layer. The rates, the the Atmosphere Explorer satellites, the adoption of the most Copyright 1981 by the American Geophysical Union. recent MSIS neutral atmosphere model $\left(\mathrm{N}_{2}, \mathrm{O}_{2}, \mathrm{O}, \mathrm{He}\right)$, and the adoption of the Engebretson et al. [1977] atomic nitrogen model. Also, our theoretical model was improved by including $\mathrm{N}^{+}$and $\mathrm{He}^{+}$in addition to the ions $\mathrm{NO}^{+}, \mathrm{O}_{2}^{+}, \mathrm{N}_{2}^{+}$, and $\mathrm{O}^{+}$.

In parallel with the improvement of our high-latitude ionospheric-atmospherioc model, we developed a simple model of high-latitude plasma convection [Sojka et al., 1979a, b; 1980a, b]. The convection model, which is based on the work of Volland [1978], includes the offset between the geographic and geomagnetic poles, the tendency of plasma to corotate about the geographic pole, and a dawn/dusk magnetospheric electric field mapped to a circular region in the ionosphere about a center offset by $5^{\circ}$ in the antisunward direction from the magnetic pole [Meng et al., 1977]. This simple convection model led to a number of important conclusions: (1) The plasma convection pattern observed either by satellites or from the ground shows a UT dependence because of the motion of the geomagnetic pole about the geographic pole; (2) The UT variation of the plasma flow pattern occurs on a time. scale that is comparable to satellite orbital periods, and that is much less than typical plasma convection flow times over the polar cap; (3) In the geographic inertial frame, the main region of very low speed flow is not centered at 1800 local time (LT) but moves from about 1300 to 2300 LT during the course of a day; (4) In the geographic inertial frame, a throatlike feature appears at certain universal times due to the relative motion of the geographic and geomagnetic poles; and (5) For magnetospheric cross-tail potentials typical of quiet conditions, a region of low-speed flow appears in the dawn polar cap sector; this feature is also UT dependent.

In order to determine the extent to which the simple convection model could account for specific observations, plasma convection patterns predicted by the model were compared with those observed concurrently at Chatanika, Alaska, and Millstone Hill, Massachusetts [Sojka et al., 1980a]. These two incoherent scatter facilities operated over the same period of four days in June 1978 and provided data sets that were averaged to 24 hours in order to minimize the effects of individual substorms. The two radar facilities observed different diurnal patterns of horizontal plasma convection velocities even though the measurements covered approximately the same range of magnetic latitudes, a feature predicted by the convection model. In general there was good agreement between the convection model and the different diurnal patterns observed at Chatanika and Millstone Hill.

Encouraged by the good agreement between the predictions of the plasma convection model and measurements we combined the convection and ionospheric-atmospheric models in order to study the high-latitude winter $\mathrm{F}$ region at solar minimum for low magnetic activity. Our numerical study produced time dependent, three-dimensional ion density distributions for the ions $\mathrm{NO}^{+}, \mathrm{O}_{2}{ }^{+}, \mathrm{N}_{2}{ }^{+}, \mathrm{O}^{+}, \mathrm{N}^{+}$, and $\mathrm{He}^{+}$. We covered the highlatitude ionosphere above $54^{\circ} \mathrm{N}$ magnetic latitude and at altitudes between about 160 and $800 \mathrm{~km}$ for one complete day. The main result we obtained was that high-latitude ionospheric features, such as the 'main trough,' the 'ionization hole,' the 'tongue of ionization,' the 'aurorally produced ionization peaks,' and the 'universal time (UT) effects,' are a natural consequence of the competition between the various chemical and transport processes mentioned above.

It should be noted that there were two previous model studies of the high-latitude ionosphere [Knudsen, 1974; 
Knudsen et al., 1977; Watkins, 1978]. Knudsen, using an early version of our ionospheric-atmospheric model and his own convection model, showed that antisunward plasma convection over the polar cap could produce a tongue of ionization and that the main trough could result from ordinary ionic recombination in combination with long decay times. Watkins [1978] developed a numerical model of the electron density at $300 \mathrm{~km}$ over the polar region and studied the extent to which seasonal variations and changes in the convection pattern affect the electron density. In addition, Watkins showed that the UT response of the ionosphere produces large diurnal changes in both the polar cap densities and the trough morphology.

Although the numerical models used by Knudsen et al. [1977] and Watkins [1978] were useful in displaying some of the gross features associated with plasma convection, the predictions they produced with regard to the detailed structure of the high-latitude ionosphere are not reliable because of the limitations associated with the models. In particular, Knudsen et al. [1977] ignored the displacement between the geomagnetic and geographic poles and hence did not take account of the large UT effect on ionospheric densities, while Watkins [1978] did not rigorously take account of vertical diffusion. Also, in both studies the plasma trajectories were traversed just once or twice, whereas reliable ion densities are obtained only if all of the plasma trajectories are followed many times, starting at different universal times.

\section{Dynamic High-Latitude Ionosphere Model}

As was noted earlier, our dynamic high-latitude ionosphere model was obtained by combining our time dependent atmosphere-ionosphere density model and our plasma convection model. Our atmosphere-ionosphere density model has recently been updated and extended; the details of the model, including ion chemistry and transport equations, are given by Schunk and Raitt [1980] and are not repeated here. In a typical calculation a magnetic field tube of plasma is followed as it moves along a convection trajectory through a corotating neutral atmosphere. Altitude profiles of the ion densities are obtained by solving the appropriate ion continuity, momentum, and energy equations, including numerous high-latitude processes [cf. Schunk et al., 1975, 1976; Schunk and Raitt, 1980].

Our convection model includes the offset between the geographic and geomagnetic poles, the tendency of plasma to corotate about the geographic pole, and a dawn/dusk magnetospheric electric field mapped to a circular region in the ionosphere about a center offset by $5^{\circ}$ in the antisunward direction from the magnetic pole. The radius of the circle corresponds to $17^{\circ}$ of latitude and the electric potentials are aligned parallel to the noon/midnight meridian within the circular region. Equatorward of the circle the potential diminishes radially and varies inversely as the fourth power of sine magnetic colatitude. Further details of our convection model are given by Sojka et al. [1979a, 1980a].

The two models described above were run sequentially for each of 23 selected plasma convection trajectories. These 23 trajectories were chosen to give a uniform coverage in the MLT frame, where they are UT independent. For each of the trajectories the convection model produced a data set containing the following parameters at regular spatial steps around the trajectory: geographic location, convection velocity, up/down induced drift, solar zenith angle, inside/outside auroral oval, dip angle, and universal time. Each trajectory was repeated a total of 12 times starting at two hourly UT intervals to obtain the required UT coverage. This data set was then used as an input to the ion density model. At the start of each trajectory the ion density model computed the steady state density profiles; for all subsequent steps the 'real time' parameter was used to recompute the composition, taking into account all of the parameters described above. Since most of the trajectories could be started near noon, in sunlight, the steady state starting profiles were found to be consistent with the time dependent results. Densities for $\mathrm{NO}^{+}$ $\mathrm{O}_{2}^{+}, \mathrm{O}^{+}, \mathrm{N}_{2}^{+}$, and $\mathrm{N}^{+}$were stored at $20-\mathrm{km}$ interval between 160 and $800 \mathrm{~km}$ for each step. Upon completion these 23 trajectory runs, each for 12 UT start times, a numerical data base representing the time-dependent polar ionosphere had been created.

The time-dependent polar ionosphere studied in this paper had been selected to highlight the universal time influence inferred in our previous convection studies. By choosing low magnetic activity conditions, and consequently, a low magnetospheric cross-tail potential $(20 \mathrm{kV})$ we minimized the transient substorm effects that are associated with more active conditions. In addition, we decided to model the northern polar ionosphere in winter at solar minimum. This choice was made because of the availability of satellite data [Brinton et al., 1978] and because ion density depletions are known to occur in certain regions of the high-latitude ionosphere for these conditions.

In the paragraphs that follow we describe some of the parameters that were adopted for our study and we briefly discuss the sensitivity of the $\mathrm{F}$ region ionization for parameters that are not well known.

\section{Plasma Convection}

A magnetospheric cross-tail electric potential of $20 \mathrm{kV}$ was selected to represent quiet magnetic activity. Figure 1 shows 10 convection trajectories in the magnetic quasi-inertial frame. Magnetic longitude is shown by tick marks at $10^{\circ}$ intervals around the outer circle, which represents a magnetic latitude of $50^{\circ}$. In addition, the key MLT values are shown. The inner circles represent magnetic latitudes at $10^{\circ}$ intervals from $60^{\circ}$ to $80^{\circ}$. Field tubes of plasma following trajectories 1 and 2 essentially corotate, hence they take 24 hours to convect around. Trajectories 3 and 4 pass near a stagnation region situated at $70^{\circ}$ latitude and $20 \mathrm{MLT}$, and consequently, plasma field tubes following these trajectories take over one day to convect around ( $\sim 1$ 1/3 days). Field tubes of plasma following the trajectories that cross the polar cap region ( 7 and 8 ) take from $1 / 3$ to $1 / 2$ day, while those following the trajectory 10 take about one day to convect around.

\section{The Quiet Time Auroral Oval}

The widely different convection times together with the time dependence of the terminator position in the magnetic frame are the source of the UT dependence that our three dimensional composition model will display. Figure 2 shows how the terminator, auroral oval, and plasma convection trajec-

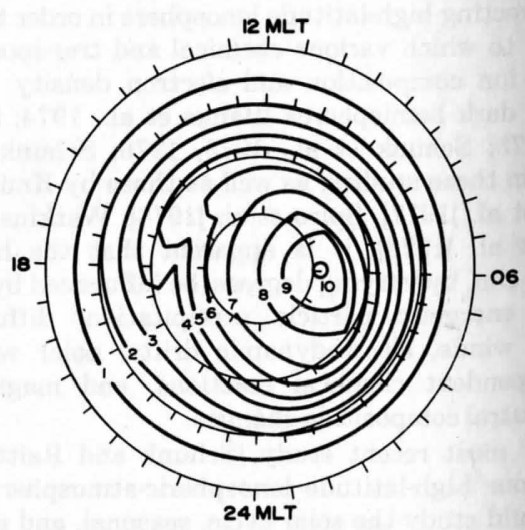

Fig. 1. Plasma drift trajectories over the polar cap viewed in magnetic quasi-inertial frame. These trajectories were calculated with allowance for corotation and a magnetospheric electric field with a total cross-tail potential of $20 \mathrm{kV}$. Magnetic latitude is represented by circles at $10^{\circ}$ intervals and magnetic longitude is represented by tick marks along these circles. 
tory are coupled. A trajectory that passes near the stagnation region was selected as a test trajectory. The terminator at one particular UT is shown; in one day the terminator moves a total of $22^{\circ}$ as the magnetic pole rotates about the geographic pole. As is shown in Figure 2, most of the polar cap is in darkness. The auroral oval, however, is a source of ionization in the dark hemisphere. For our calculations we selected the quiet time oval of Feldstein and Starkov [1967]. For the UT shown the test trajectory lies in the dark hemisphere; however, it does enter the evening sector oval. This test trajectory was used to study the sensitivity of the $\mathrm{F}$ region ionization to some of our adopted parameters and the results are discussed below.

Auroral and Resonantly Scattered Radiation Production

In addition to ion production due to EUV radiation, we also considered auroral particle precipitation and resonantly scattered radiation as sources of ionization. The production due to resonantly scattered radiation is small in comparison with that due to auroral precipitation and direct EUV radiation, and therefore it only affects the F layer in the dark hemisphere outside the auroral zone. The resonantly scattered radiation production rate profiles for $\mathrm{O}^{+}, \mathrm{N}_{2}{ }^{+}$, and $\mathrm{O}_{2}^{+}$that we adopted are shown in Figure 3; these profiles were taken from Knudsen et al. [1977].

Our auroral oval production rates were also taken from Knudsen et al. [1977]. These production rates, which are shown in Figure 3, correspond to moderately active evening sector precipitation. Although these auroral production rates are appropriate only for the evening sector, we adopted them for the entire auroral oval. In regions where softer precipitation is present, the altitude variation of the production rates may be different from that shown in Figure 3. However, there is a problem with obtaining reliable auroral oval production rates because the particle precipitation is highly time dependent and because the oval location is known only statistically. Therefore, in this study we did not attempt to obtain rigorous auroral ion production rates at all local time sectors; instead, we adopted reasonable ion production rates so that we could determine the extent to which this mechanism affects ionospheric densities. However, we also varied both the magnitudes of the ion production rates and the location of the oval to test the sensitivity of our results to these parameters.

$\underline{\text { Ion and Electron Temperature Profiles }}$

The ion and electron temperatures affect the ion densities through temperature dependent chemical reaction rates and dif-

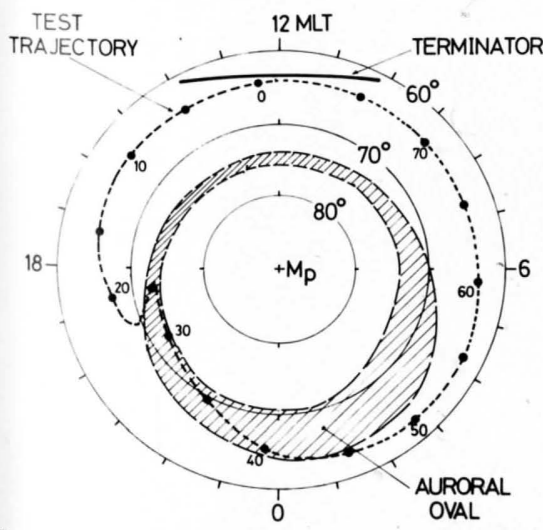

Fig. 2. The location of a northern hemisphere, quiet time line is oval in the magnetic quasi-inertial frame. The dashed me is the test trajectory that was used to study nighttime are indince processes; the step numbers around the trajectory locaticated by dots at every fifth step. The solid line shows the location of the winter terminator at one universal time.
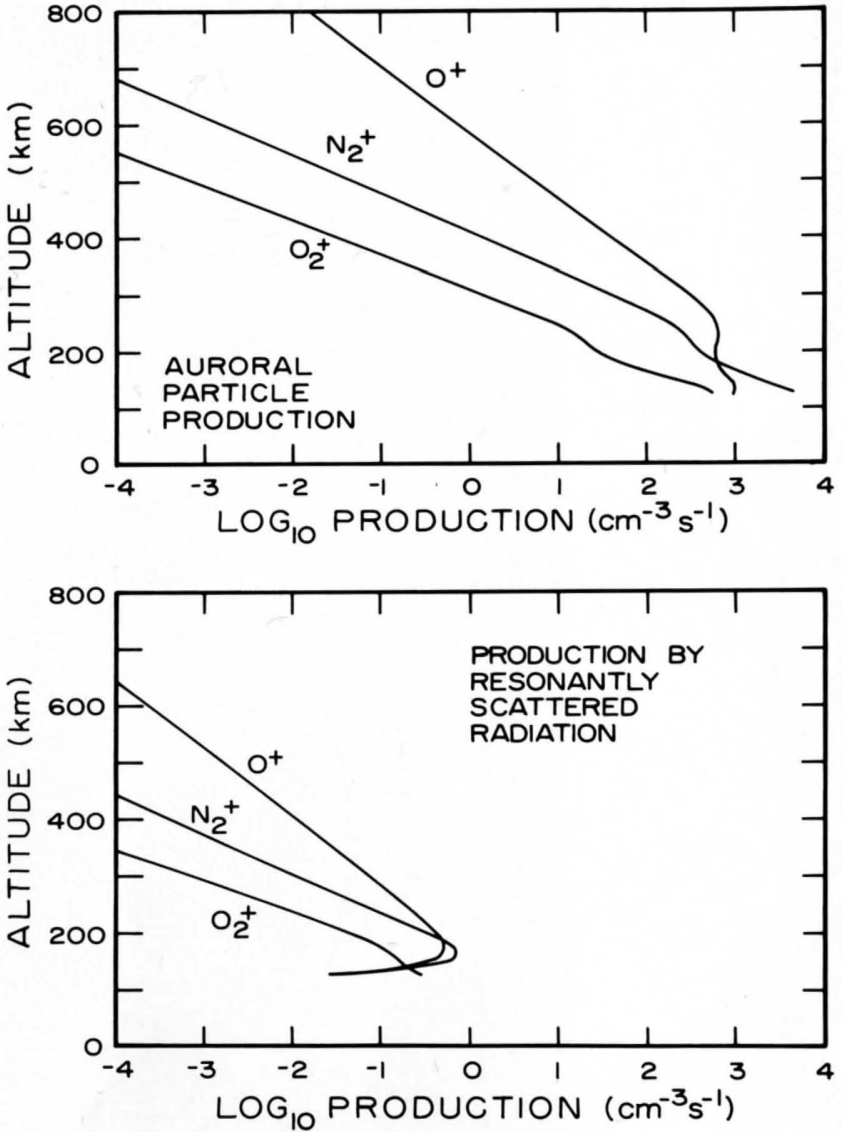

Fig. 3. Adopted ion production rates versus altitude for (top panel) auroral particle precipitation and for (bottom panel) resonantly scattered solar radiation.

fusion coefficients [cf. Schunk and Raitt, 1980]. In our model calculations we did not solve the electron energy balance equation to obtain electron temperatures; instead, we adopted different profiles for different regions of the high-latitude ionosphere. The different regions we considered were the auroral oval and the sunlit and dark hemispheres. The adopted electron temperature profiles for these regions are shown in Figure 4 The daytime and nighttime profiles were taken from Roble [1975], while the auroral oval profile was taken from Roble and Rees [1977].

With regard to the ion temperature, we solved the ion energy balance equation, including coupling to the neutrals and frictional (Joule) heating. Since ion thermal conduction and coupling to the electrons were ignored, the resulting ion temperatures are valid only below about $300-500 \mathrm{~km}$, depending on ionospheric conditions. Therefore, to obtain a better ion temperature profile at high altitudes, we adopted a specific 'shape' for the profile above $300 \mathrm{~km}$ and tied it to the calculated ion temperature at $300 \mathrm{~km}$. This procedure allowed us to take account of the important effect that electric field induced frictional heating has on the ion temperature. When frictional heating is small the ion temperature at $300 \mathrm{~km}$ is essentially tied to the neutral temperature. Figure 4 shows representative daytime and nighttime ion temperatures for this latter case.

\section{Nocturnal Maintenance Processes}

The depth of the 'main trough' or 'polar hole' may well depend on nocturnal maintenance processes, such as downward diffusion of ionization from high altitudes, production due to resonantly scattered radiation, production due to weak particle 

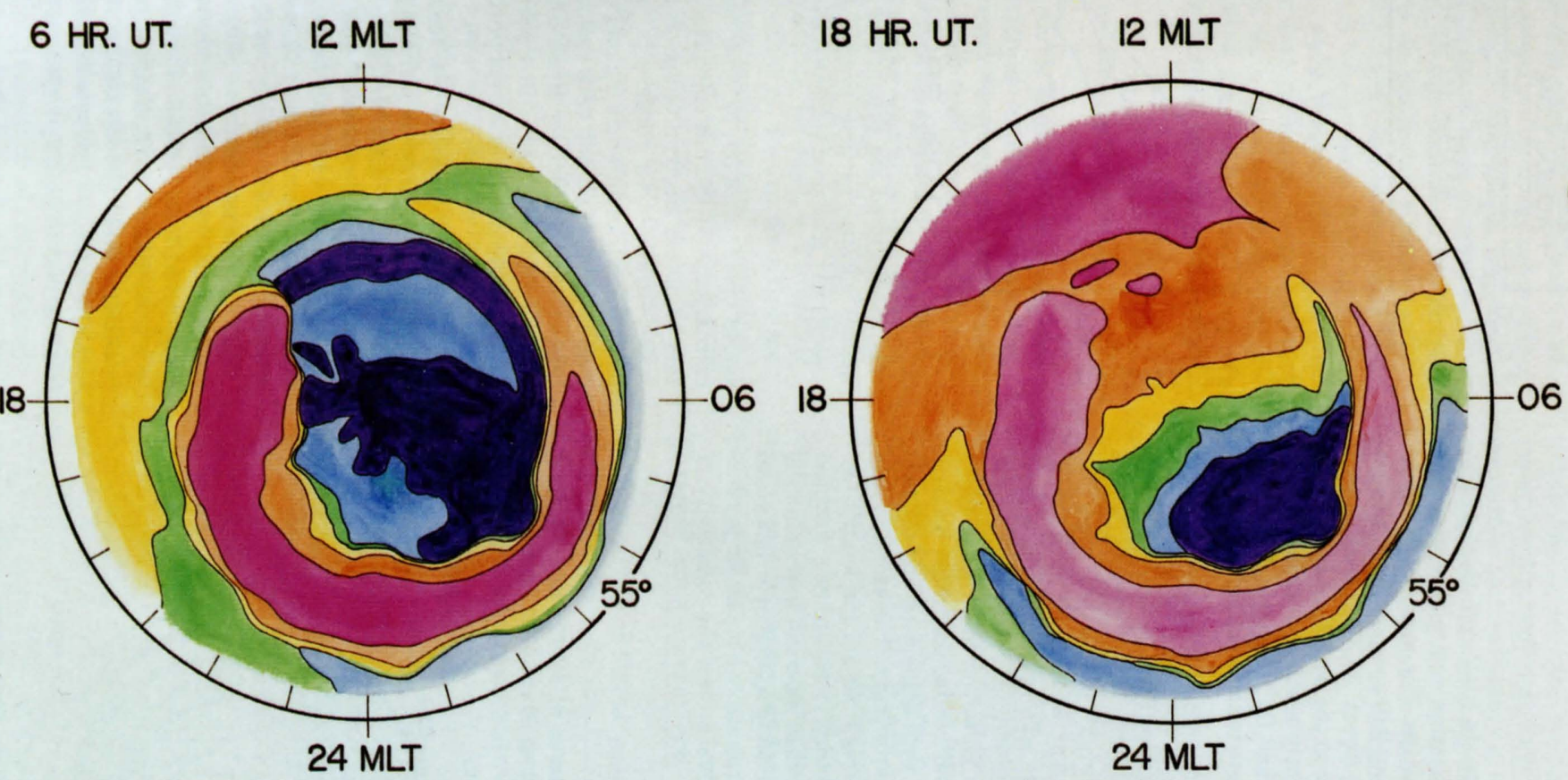

\section{DENSITY COLOUR KEY}

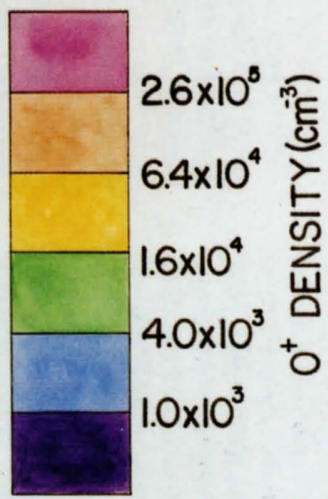

Plate $1 . \mathrm{O}^{+}$density contours at $300 \mathrm{~km}$ in the magnetic quasi-inertial frame for two universal times. The location of the geographic pole at these universal times is shown by a cross. Note that the density contours cover three orders of magnitude. 

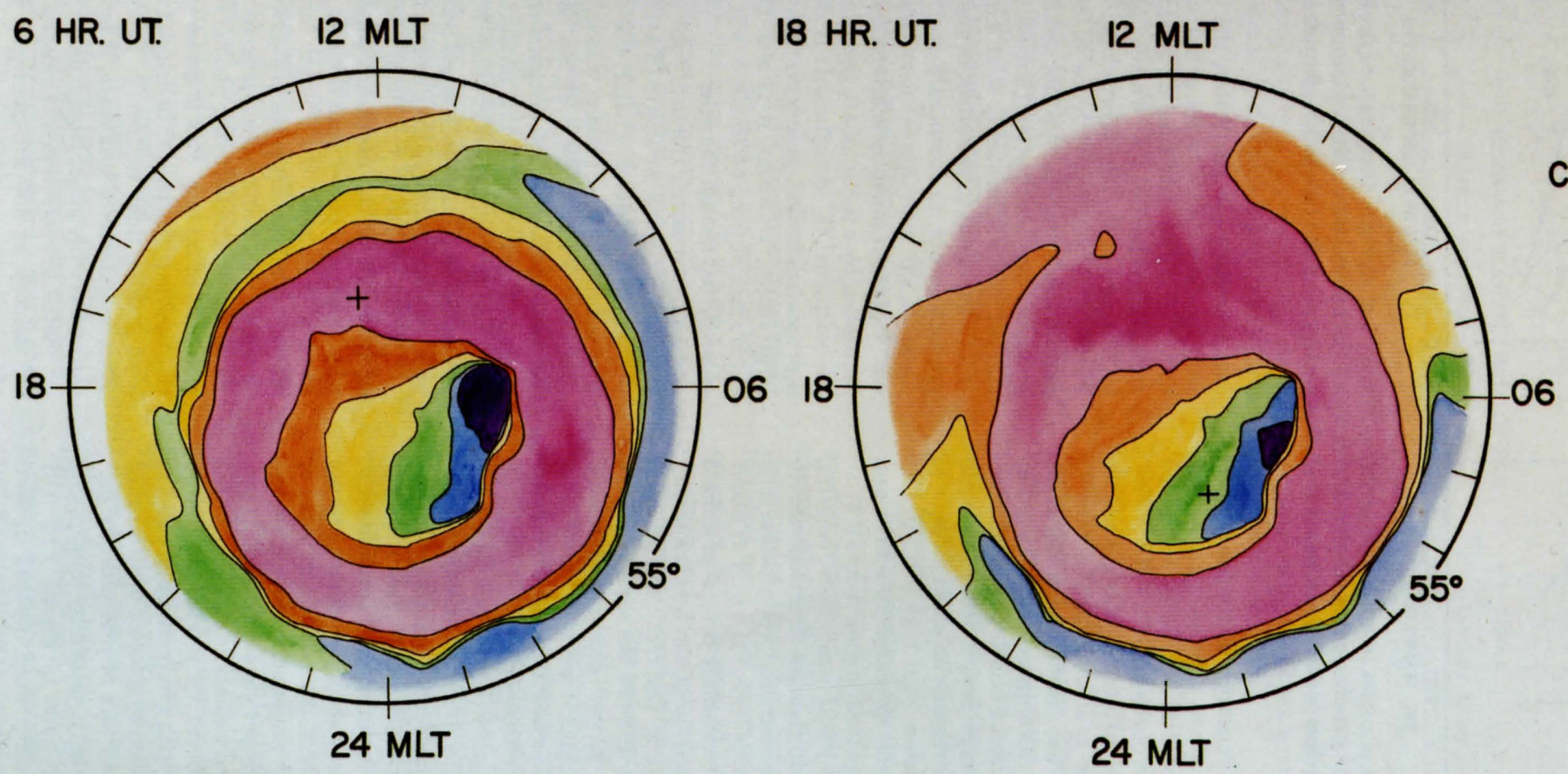

\section{DENSITY \\ COLOUR KEY}

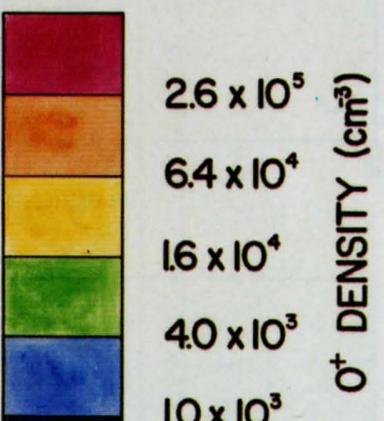

Plate $2 \mathrm{O}^{+}$density contours at $300 \mathrm{~km}$ in the magnetic quasi-inertial frame for two universal times. These contours were obtained for the same conditions that led to Plate 1, except that production due to auroral precipitation was turned off in the late morning sector of the oval. 

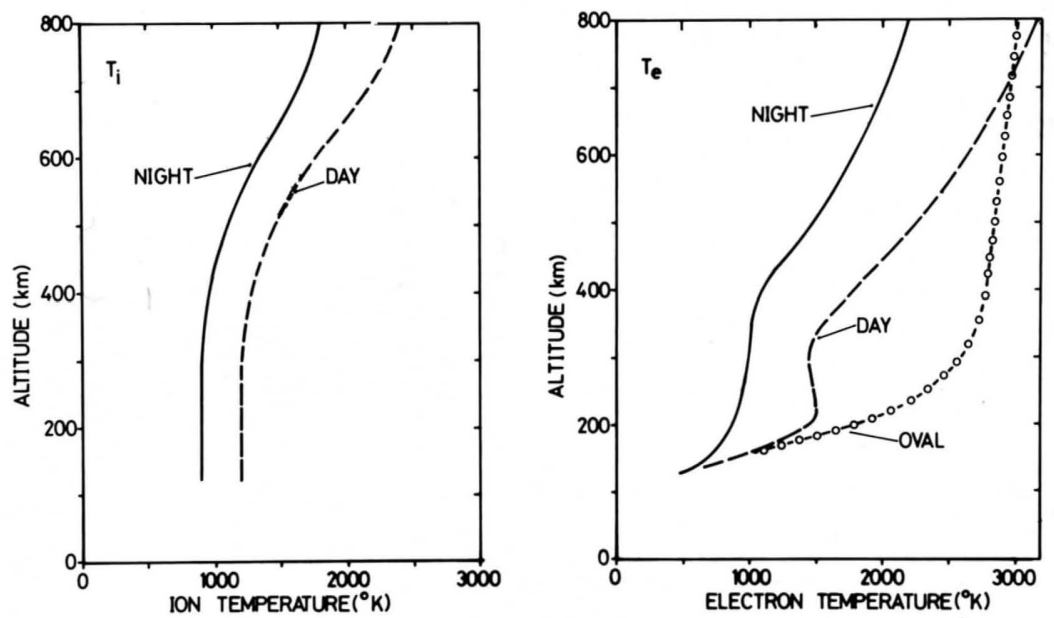

Fig. 4. Adopted ion and electron temperature profiles. Three fixed electron temperature profiles were adopted, depending on whether the plasma is in sunlight, darkness, or the auroral oval. The ion temperature profile has a fixed shape above $300 \mathrm{~km}$ but is tied to a solution of the ion energy equation below this altitude.

precipitation, and induced upward ionization drifts due to thermospheric winds. Since some of these processes cannot be rigorously accounted for in our model at this time, we studied the extent to which they could affect our results.

To study the effect of nocturnal maintenance processes, we calculated ion densities along the test trajectory shown in Figure 2 for four cases, each one including a different maintenance process. The density calculations were started at local noon, where the field tube of plasma is near the terminator. As the plasma convects around the nightside, it decays owing to the lack of photoionization. In this region the plasma tends to be maintained by downward diffusion from high altitudes as well as some of the other maintenance processes. As time progresses the field tube enters a stagnation region near 19 MLT and then convects back toward the sunlit hemisphere, entering the auroral oval. The field tube again changes direction near 18 MLT and remains in the oval, where particle precipitation acts as an ionization source. The field tube leaves the oval at about local magnetic midnight and then essentially corotates around toward local noon. A complete traversal of the test trajectory takes more than a day ( $\sim 28$ hours). On returning to local magnetic noon, the solar zenith angle is not the same as it was when the plasma started following the convection path because the relative orientation of the geomagnetic and geographic poles has changed owing to the 4 hour difference between the convection time and the corotation time (a UT effect).

Figure 5 shows the $\mathrm{O}^{+}$density at $300 \mathrm{~km}$ for two successive traversals of the test trajectory. The four curves shown correspond to the effect of different nocturnal maintenance processes. For all four cases the auroral ionization rates shown in the top half of Figure 3 were not included, and consequently, when the plasma was in darkness only the maintenance process considered opposed the decay of the F layer. The top panel of Figure 5 shows how the solar zenith angle varied along the trajectory. The four maintenance processes considered are (1) production due to resonantly scattered radiation as given in the bottom panel of Figure 3 (solid curve), (2) production due to resonantly scattered radiation but with the production rates in the bottom panel of Figure 3 multiplied by a factor of 10 (dashed curve), (3) production due to a small flux of precipitating particles, with the exact production rates obtained by multiplying the auroral rates shown in the top panel of Figure 3 by 0.01 (solid dotted curve), and (4) a neutral wind induced upward ionization drift of $30 \mathrm{~m} \mathrm{~s}^{-1}$ (dot-dashed curve).

A feature that is clearly evident in all four cases is the universal time dependence of the photoionization process, which can be seen by comparing the first and second traversals of the test trajectory. In particular, the $\mathrm{O}^{+}$density at 12 MLT can vary by more than a factor of 5 from one day to the next. Also, at 19 MLT the field tube of plasma does not come back into sunlight on the first day, whereas on the second day the plasma on this part of the trajectory is sunlit. Another feature shown in Figure 5 is the convergence of the results of the different maintenance processes to the same density at local noon. This validates our assumption that each of our trajectories can be started from a noon steady state ion density profile.

With regard to the effect of the maintenance processes, ion production due to resonantly scattered radiation, as given in Figure 3 , can maintain $\mathrm{O}^{+}$densities at $300 \mathrm{~km}$ at about $5 \times 10^{2}$ $\mathrm{cm}^{-3}$. If the resonantly scattered radiation production rates are multiplied by a factor of 10 , there is a corresponding increase in the nocturnal $\mathrm{O}^{+}$densities. It is doubtful that our resonantly scattered radiation production rates are uncertain by such a large factor. However, it is also clear that an uncertainty in these rates of from 50 to $100 \%$ will have an appreciable impact on predicted trough densities.

As noted earlier the field tube of plasma enters the auroral oval and stagnates at about 19 MLT. The plasma then remains in the oval until about 1 MLT. For one of our cases we assumed that the ionospheric plasma was subjected to particle precipitation while it was in the oval, but the ion production rates were assumed to be only $1 \%$ of the normal auroral ionization rates given in Figure 3. With this production level, nocturnal $\mathrm{O}^{+}$densities can be maintained at about $6 \times 10^{3} \mathrm{~cm}^{-3}$ in the region of precipitation. Therefore, a small flux of 'hard' precipitating particles can appreciably affect trough densities.

In the region of the main trough, which is situated just equatorward of the nocturnal auroral oval, the thermospheric wind generally blows from the pole toward the equator. Such a wind acts to raise the $\mathrm{F}$ layer ionization to higher altitudes where recombination rates are slower. To determine the extent to which this maintenance process can affect trough densities, we subjected the decaying plasma to a constant upward ionization drift of $30 \mathrm{~m} \mathrm{~s}^{-1}$ as it traversed the test trajectory. With this upward drift the $\mathrm{O}^{+}$density at $300 \mathrm{~km}$ was maintained at a level greater than $10^{3} \mathrm{~cm}^{-3}$. Therefore, as was found for the other maintenance processes, a small upward ionization drift can appreciably affect trough densities.

Satellite measurements indicate that in the main trough the $\mathrm{O}^{+}$density at $300 \mathrm{~km}$ generally is greater than $10^{3} \mathrm{~cm}^{-3}$. However, if resonantly scattered radiation is considered as the only nocturnal maintenance process, the $\mathrm{O}^{+}$density at $300 \mathrm{~km}$ decreases to about $5 \times 10^{2} \mathrm{~cm}^{-3}$. This suggests that other maintenance processes are operating in the main trough in addi- 


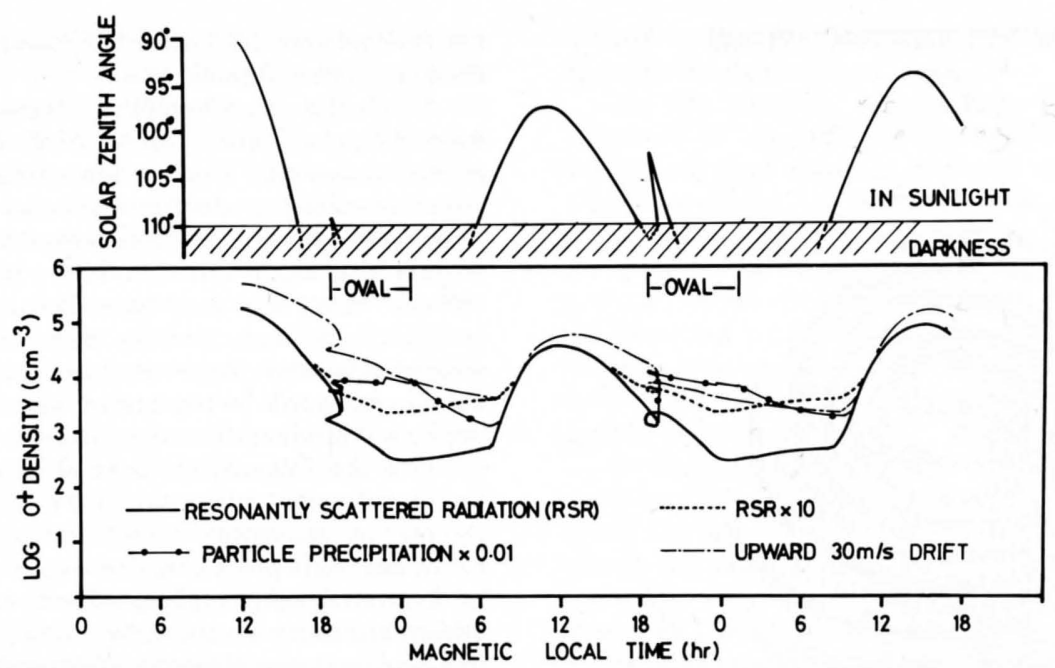

Fig. $5 . \mathrm{O}^{+}$density at $300 \mathrm{~km}$ versus magnetic local time as the plasma follows the test trajectory. Four different cases are shown to display the effect of different nighttime maintenance processes, including resonantly scattered radiation, an enhancement by a factor of 10 in resonantly scattered radiation, weak particle precipitation, and an induced upward plasma drift. The top panel shows when the plasma is in sunlight.

tion to resonantly scattered radiation. From the above discussion it is apparent that there are several processes that are capable of maintaining the $\mathrm{O}^{+}$density at the $10^{3} \mathrm{~cm}^{-3}$ level. Therefore, to simulate their effect we increased the resonantly scattered radiation production rates shown in Figure 3 by a factor of 4 in the region of the main trough. However, except for the main trough and the auroral oval, only resonantly scattered radiation was considered as a maintenance process for the other regions of the dark hemisphere.

\section{High-Latitude Ionospheric Structure}

\section{Computational Details}

The plasma convection model and the ionospheric composition model described above were combined to generate altitude profiles of the various ionic species from 160 to $800 \mathrm{~km}$ over the general area poleward of $54^{\circ}$ magnetic latitude, covering all local times and all universal times. The neutral atmosphere used in the computations corresponded to the following conditions: solar minimum, northern hemisphere, winter, and low magnetic activity. The cross-tail magnetospheric potential was chosen to be $20 \mathrm{kV}$ to be consistent with the low magnetic activity parameter used in the MSIS neutral atmospheric model.

In order to obtain adequate coverage in three-dimensional space and in universal time, the region of computation was divided up as follows. The altitude profiles consisted of ion densities computed every $4 \mathrm{~km}$ from $160 \mathrm{~km}$ to $800 \mathrm{~km}$. Twentythree drift trajectories were chosen to give adequate spatial coverage over the high-latitude region, and each of the trajectories was traversed 12 times, corresponding to 12 different UT starting times that were separated by 2 hours. As the plasma convected around its trajectory, universal time was allowed to progress correctly, as determined by the changing velocity of the plasma at different trajectory locations.

Each traversal of a trajectory was started by first obtaining steady state ion density profiles at local noon. Tests on the calculations showed that it was a valid assumption to use steady state profiles computed at local noon as a starting point for the time dependent solution. The time dependent program was then allowed to step around the trajectory for a period that ranged from $1 / 2$ to $11 / 3$ days. The traversal of the nearly circular corotation drift trajectories took about 1 day, while the traversal of the trajectories that pass near the stagnation region took about 1 1/3 days (see Figure 1). The time for traversing a typical small inner trajectory was about $1 / 2$ day. Along each trajectory the spatial step size for saving density profiles was determined by the condition that adjacent profiles were separated by 5 to 15 min of magnetic local time, depending on the horizontal structure. There were about 200 steps around a typical trajectory. However, in order to get better numerical time derivatives for the solution of the ion density equations, each spatial step along the trajectory was further divided into five minor steps, but only the density profiles from the fifth step were preserved.

The net results of the computations consisted of a data base containing about 22,000 altitude profiles for each of the six ion species considered. The altitude profiles were distributed in magnetic latitude, MLT, and universal time. For convenience of presentation, these three parameters were divided into bins; the bin sizes were $3^{\circ}$ for magnetic latitude, 1 hour for MLT, and 2 hours for UT. Because of the initial trajectory selection, the coverage in these bins was uniform. However, owing to the displacement between the geomagnetic and geographic poles, the coverage in the geographic inertial frame (GEI frame) was not identical to that in the magnetic frame. Figure 6 shows the locations of the ion density profiles in the GEI frame for 1 of the 12 UT bins. The coverage in the GEI frame is nonsymmetric about the pole, but otherwise the coverage is fairly uniform. This coverage was sufficient to enable us to map the ionospheric composition as functions of latitude, local time, altitude, and universal time in either the magnetic or GEI coordinate system and thereby to study the gross features of the high-latitude ionosphere.

\section{$\underline{\text { UT Effect on the } \mathrm{O}^{+} \text {Density }}$}

A convenient way to display the UT variation of the highlatitude ionosphere is by the use of contour plots of ion density at fixed altitudes. However, before we constructed contour plots for a specific ion species, we calculated average ion density profiles for each magnetic latitude - MLT-UT bin; a typical bin contained seven profiles for each ion species. Plate 1 shows the resulting contours of the $\mathrm{O}^{+}$density at $300 \mathrm{~km}$ for the 0400-0600 hour and 1600-1800 hour UT ranges. These two UT ranges were selected because they correspond to the maximum noon-midnight displacement of the geographic pole in the MLT frame. In Plate 1 the location of the geographic pole at the middle of the UT range is shown by a cross. The dynamic range of densities covered in Plate 1 is about three orders of magnitude, 


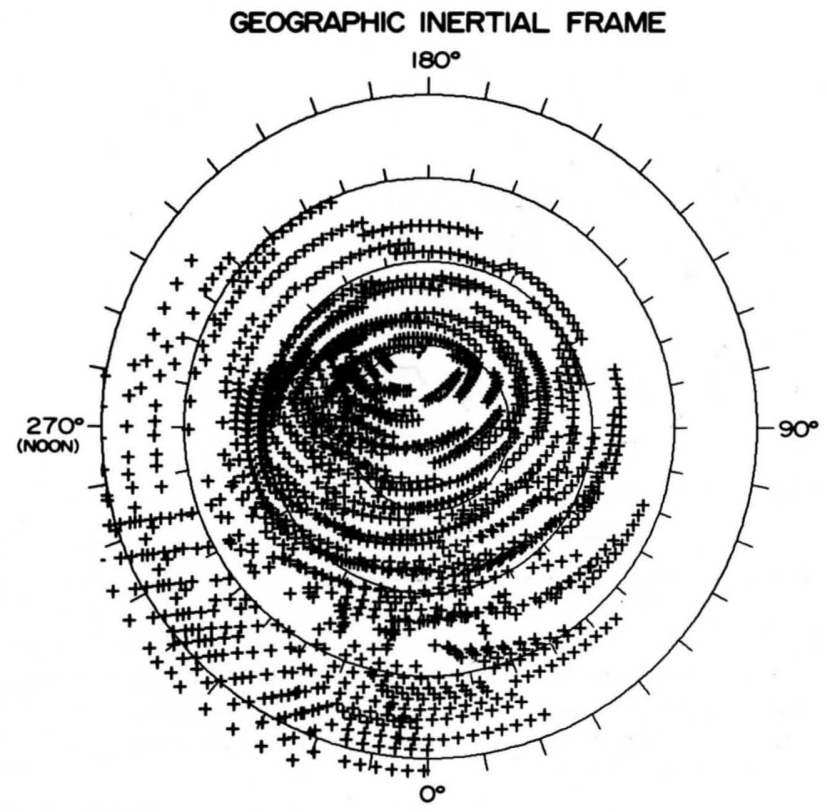

Fig. 6. Distribution of computed ion density profiles in the geographic inertial frame for one of the twelve universal time (UT) periods.

the lowest densities being below $10^{3} \mathrm{~cm}^{-3}$, while the largest extend up to $10^{6} \mathrm{~cm}^{-3}$. A logarithmic scaling factor of 4 was used to select the contour intervals, which are defined by the color key in Plate 1.

The two contour plots in Plate 1 clearly show a marked UT variation of the $\mathrm{O}^{+}$density distribution over the region poleward of $54^{\circ}$ latitude. Both contour plots show the gross features of a mid-latitude (or main) ionization trough, a ring of enhanced ionization in the vicinity of the auroral oval, and a high-latitude ionization hole around local dawn. However, the detailed characteristics of these features differ for the two UT time ranges shown. For example, the depth and extent of the mid-latitude ionization trough differ considerably. The 1600-1800 UT contour plot shows the deepest part of the trough (blue color) extending from about 2000-0600 MLT, with only a very slight trough in the morning and afternoon sectors and no trough around noon. However the 0400-0600 UT contour plot shows the deepest part extending from 2300-1000 MLT, but a distinct trough feature (green color) is also visible at all other local times.

It is interesting to note that the deepest trough in the duskmidnight sector occurs at an earlier MLT for the 1600-1800 UT range than for the $0400-0600$ UT range even though the noon/afternoon ionization level is higher for the 1600-1800 UT range. The low density plasma seen at $2100 \mathrm{MLT}$ in the trough for the 1600-1800 UT range originated from a noon region, as it did for the 0400-0600 UT case, but the plasma takes 12 hours to convect from the noon region to the trough, with the result that the plasma seen in the trough at $1600-1800$ UT is the same plasma seen at local noon at 0400-0600 UT. Likewise, the trough plasma seen at $0400-0600 \mathrm{UT}$ is the same plasma seen at local noon at 1600-1800 UT. However, the depth of the trough is determined to a large extent by the noontime ionization level. As a consequence, small noontime electron densities act to produce a deep main trough about 12 hours later, which explains why a deep trough and a high noontime electron density at a given UT are not necessarily in conflict.

Another UT effect is clearly evident on the dayside near local noon. The $1600-1800$ UT plot shows high $\mathrm{O}^{+}$densities extending to low latitudes, while the 0400-0600 UT plot shows high $\mathrm{O}^{+}$densities only in the auroral oval. This UT effect results because between $1600-1800$ UT the terminator is at its closest
distance to the magnetic pole.

Inside the auroral oval the plasma density shows very little dependence on either UT or MLT. This results because the plasma convection speed is low enough for the $\mathrm{O}^{+}$density to adjust to auroral production and because our auroral production rates were assumed to be independent of MLT. The adopted auroral production rates produce a peak $\mathrm{O}^{+}$density of about $10^{6} \mathrm{~cm}^{-3}$ near noon local time. This level of auroral production is clearly too large for the noon sector, especially for low magnetic activity. However, the effect of these high auroral pro duction rates will be contrasted with the effect of a purely UT dependent production source in a later section of the paper.

Over the polar cap the density contours radiate from a point on the poleward edge of the oval at dawn. This effect is due to the relative convection speeds across the polar cap; the trajec tories near this point take one day to circulate, whereas those furthest away take only half a day to complete a loop. There are a few trajectories (cf. trajectory 10 in Figure 1) that do not enter the oval and are therefore independent of the oval. Consequently, in this region (violet color) the plasma densities below $10^{3} \mathrm{~cm}^{-3}$ show the most variation between the two UT ranges shown. In this so-called 'ionization hole' the plasma density drops as low as $2 \times 10^{2} \mathrm{~cm}^{-3}$ because, unlike the mid-latitude trough, the only nocturnal maintenance process considered for this region was ion production due to resonantly scattered radiation, as given in Figure 3. In this region the magnetic field lines are nearly vertical, and hence, neutral wind induced vertical ionization drifts are not an effective nocturnal maintenance process.

The $\mathrm{O}^{+}$density contours shown in Plate 1 can be compared with the Atmosphere Explorer (AE) satellite measurements of Brinton et al. [1978]. Brinton et al. show the variation of the minimum and maximum $\mathrm{O}^{+}$density at $300 \mathrm{~km}$ above the highlatitude polar region. Although these data correspond to roughly the same geophysical conditions that were adopted for our calculations, it is not possible to do a detailed comparison because the data presented are incomplete and because no account was taken of the UT dependence of the high-latitude ionosphere when the data were plotted. Also, from the theoretical point of view our model is uncertain with regard to the depth of the main trough because the depth is sensitive to nocturnal maintenance processes, which are not quantitatively well known. Nevertheless, the comparison of our model predictions with the gross features of the AE data produces some useful results. First, both the data and the model predictions display ionospheric features such as the main trough, the polar hole, and the enhanced ionization in the auroral oval. However, our $\mathrm{O}^{+}$densities in the oval are much larger than the measured ones, and this probably indicates that our auroral production rates are too large because the plasma convection calculations correspond to quiet geomagnetic activity conditions, while the auroral production rates correspond to moderately active evening sector precipitation. Also, the polar hole is less apparent in our plots and its location is slightly different from that measured by the AE satellite. This point will be discussed in more detail in a later subsection. As a final item we note that the maximum and minimum $\mathrm{O}^{+}$density plots display main troughs that are different in extent and form. Our model predicts a UT variation of the extent and form of the main trough, but it is not clear whether or not the variation presented by Brinton et al. [1978] is related to a UT effect because their plots were constructed from data gathered at different universal times.

\section{Simulated Satellite Measurements}

An important result to emerge from our study is that some ionospheric processes can be better analyzed in certain reference frames. For example, since the terminator is essentially fixed on the time scale of several days in the GEI frame, effects related to solar radiation should be studied in this frame. Likewise 
since the auroral oval and the convection electric field are related to magnetospheric effects, they should be studied in the MLT frame. However, because of the competition between the various high-latitude processes, neither the GEI nor the MLT frame is completely satisfying. Also, the UT dependence of the high-latitude ionosphere introduces a further complication with regard to the interpretation of either ground-based or satellite measurements.

To determine exactly what is observed in a given reference frame, we simulated a $300-\mathrm{km}$ circular satellite orbit that traverses the polar region in the dawn-dusk plane, and we plotted the $\mathrm{O}^{+}$densities that would be observed along the satellite track in both the GEI and MLT frames. The results are shown in Figure 7, with the left panels corresponding to the GEI frame and the right panels to the MLT frame. The top panel of each column shows two simulated satellite trajectories a half day apart (0800 and 2000 UT), as viewed in the GEI and MLT frames. The $\mathrm{O}^{+}$densities that would be observed along these satellite tracks are shown in the middle panels, while the bottom panels show the $\mathrm{O}^{+}$densities that would be observed along a series of orbital tracks. In these panels, negative colatitude is
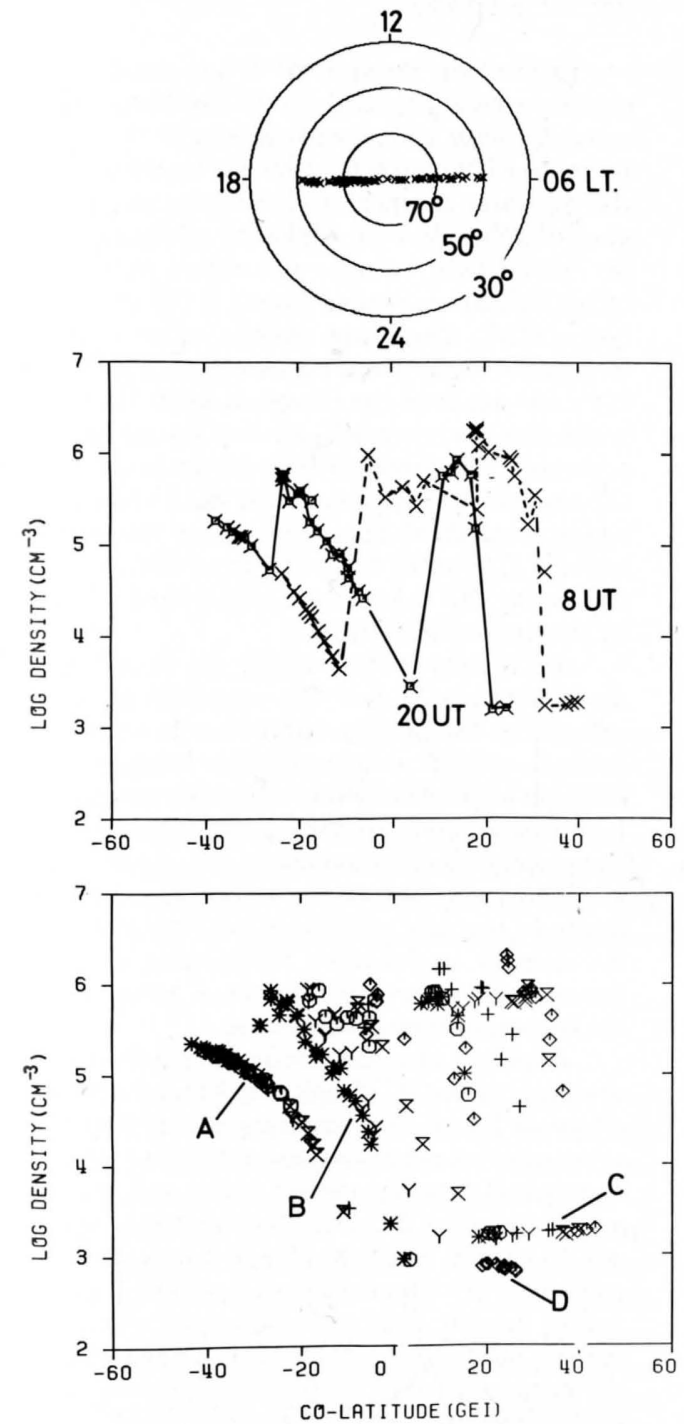

defined to be in the dusk sector, while positive values correspond to the dawn sector.

As the satellite moves from dusk toward dawn, the 'observed' $\mathrm{O}^{+}$density first decreases in the region of the main trough and then abruptly increases as the satellite enters the auroral oval. For the $0800 \mathrm{UT}$ orbit the $\mathrm{O}^{+}$density remains enhanced until the satellite leaves the oval on the dawnside. For the 2000 UT orbit, on the other hand, the satellite leaves the oval and enters the polar cap, which at this time contains low $\mathrm{O}^{+}$densities, with the minimum in the $\mathrm{O}^{+}$density occurring near the location of the polar hole. For this 2000 UT orbit, the satellite then enters the dawnside of the auroral oval and the $\mathrm{O}^{+}$ density increases again.

In the GEI frame the two orbits show very different locations for the equatorward edge of the oval, while in the MLT frame the equatorward edge of the oval appears at approximately the same location for the two orbits. Also, in the GEI frame the variation of the $\mathrm{O}^{+}$density with colatitude in the afternoon trough is similar for both orbits, while in the MLT frame this variation is different for the two orbits. These results demonstrate the importance of displaying and analyzing data in
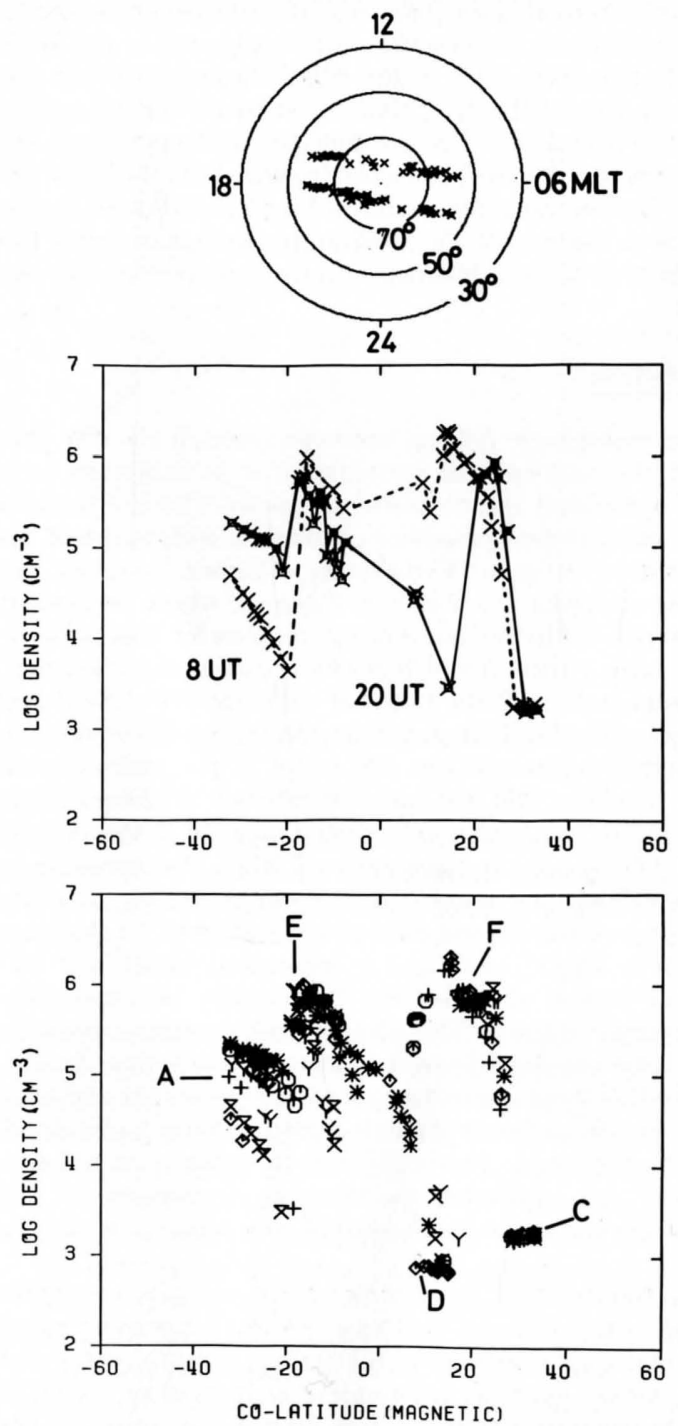

Fig. 7. Simulated satellite crossings of the northern polar cap in the dawn-dusk plane at $300 \mathrm{~km}$. The top panels show two representative crossings 12 hours apart in both (left panel) the geographic inertial frame and (right panel) the magnetic quasi-inertial frame. The center panels display the $\mathrm{O}^{+}$density along the satellite track for these crossings in both (left panel) the geographic inertial frame and (right panel) the magnetic quasi-inertial frame. The bottom panels display the $\mathrm{O}^{+}$density along the satellite track for one full day. A number of features are identified by capital letters and are discussed in the text. 
the reference frame of the dominant or controlling process. In the main trough the densities vary systematically in the GEI frame, while in the auroral oval they vary systematically in the MLT frame. A region like the polar cap is more complex, since even if particle precipitation is not important, the coupling of magnetospheric convection and solar radiation processes makes it difficult to find a unique reference frame for data presentation.

The bottom panels in Figure 7 show the confusion that could arise from accumulating and displaying data from a whole days worth of satellite crossings of the polar region. Each symbol in these panels represents data from a particular satellite crossing. As with real satellite data, the interpretation of the results is not always straightforward. However, with the knowledge of what our model predicts it is possible to identify some of the key ionospheric features in these two panels.

Region A in the GEI frame shows how the trough densities vary smoothly with colatitude, while in the MLT frame this region is rather variable. In the GEI frame, region $B$ shows a higher density band parallel to region $\mathrm{A}$, which corresponds to plasma field tubes that have entered the oval, enhanced their densities, left the oval in the polar region, and then proceeded to convect toward dusk. This band is not clearly seen in the MLT reference frame. Feature E in the MLT frame represents the equatorward edge of the oval; there is no single corresponding feature in the GEI frame. The low densities in the polar hole are feature D, while the morning sector trough characteristics are feature $\mathrm{C}$. The morning sector auroral oval is indicated in the MLT frame as feature F. This feature in particular shows the effect of the high auroral production rates that were used in our model.

\section{Ion Composition}

As the ionospheric plasma convects through the different regions of the high-latitude ionosphere, it is subjected to a myriad of dynamical and chemical processes. The competition between these different processes produces a wide range of ion compositions in the polar $\mathrm{F}$ region at different locations and times. Four examples are shown in Figure 8, where we present altitude profiles of the various ionospheric ions for selected locations and times. Panels A and B are for the same MLT location, near the polar hole of Plate 1, but at different UT's (2400 and 0500 , respectively). In both examples the peak electron density is considerably below $300 \mathrm{~km}$. For panel A the peak electron density is at about $200 \mathrm{~km}$ and is composed of almost equal amounts of $\mathrm{NO}^{+}, \mathrm{O}_{2}{ }^{+}$, and $\mathrm{O}^{+}$, while for panel $\mathrm{B}$ the peak is located at $170 \mathrm{~km}$ and is essentially all $\mathrm{NO}^{+}$. The densities in panel $\mathrm{C}$ are from the polar cap at local midnight near the poleward edge of the auroral oval at a UT of 2100 . In this case the $\mathrm{F}$ peak is an $\mathrm{O}^{+}$peak and is located at about $240 \mathrm{~km}$; however, at higher altitudes the $\mathrm{N}^{+}$density becomes comparable to the $\mathrm{O}^{+}$density. This plasma has convected across the polar cap from the dayside oval in about $1 / 3$ of a day. In contrast, panel D is from inside the oval at local midnight and 0600 UT. Here the effect of auroral particle production is highlighted. The dominant $\mathrm{F}$ region ion is $\mathrm{O}^{+}$and the peak is at $240 \mathrm{~km}$; however, at low altitudes the auroral production of the molecular ions is evident in the form of enhanced molecular ion densities.

An alternative view of ion composition variations is shown in Figure 9. In this figure, densities at $300 \mathrm{~km}$ have been plotted along the test trajectory shown in Figure 2. The trajectory was started at local noon with the terminator located as shown in Figure 2. In the course of convecting around the trajectory the plasma entered the auroral oval, remained in it a certain time, and then left it at about local magnetic midnight. In Figure 9 the location around the trajectory is shown as a step number beginning at noon, each step corresponds to $80 \mathrm{~km}$. The same trajectory was followed twice, once with (dashed curves) and once without (solid curves) allowance for auroral particle production. Also shown in the figure is the extent of the auroral
oval.

When the plasma entered the oval, the ion densities in both cases increased. The reason for the increase in the case of no auroral production is that the convection direction reversed and the plasma moved into sunlight again (see Figure 2, $18 \mathrm{MLT}$ ). After leaving the oval, $\mathrm{O}^{+}$, which was the dominant ion in both cases, had a significantly higher density in the case of particle precipitation. A direct consequence of the enhanced $\mathrm{O}^{+}$and electron densities was that the loss rate for the minor molecular ions was increased. After the plasma left the region of particle production, the auroral source of molecular ions disappeared, but the loss rate remained high. Consequently, the minor molecular ions, whose time constant for recombination was fast in comparison with $\mathrm{O}^{+}$, decayed rapidly, and their densities fell below those found at these locations for the case of no earlier auroral particle production. The composition observed in the region beyond the oval is directly related to the earlier history of the plasma as it convected around the polar region.

\section{The Main Trough}

Earlier we noted that a low-density region exists just equatorward of the auroral oval (see Plate 1 and Figure 7). In the evening sector the plasma density in this region was found to decrease with increasing latitude until the equatorward edge of the oval was reached, and then the plasma density increased abruptly. This feature, which has all the signatures of the 'main' or 'mid-latitude' trough, was shown to be UT dependent. The trough minimum ranged from $3 \times 10^{3} \mathrm{~cm}^{-3}$ to $10^{5} \mathrm{~cm}^{-3}$ at 18 hours MLT. The lower density value of $3 \times 10^{3} \mathrm{~cm}^{-3}$ was largely the result of our nocturnal maintenance processes. At all UT's the depth of the trough at 0600 MLT reached $10^{3} \mathrm{~cm}^{-3}$, which was the lower limit allowed by our nocturnal maintenance processes. The lowest trough densities occurred in the morning sector, and the greatest extent of the trough into the morning sector occurred when the terminator was at its lowest midnight latitude. The total MLT extent of the trough varied with UT; the extent can range from 1800-0600 MLT or from 1500-1000 MLT, depending on the UT.

A difficulty with modeling the main trough is that there is an uncertainty in how the auroral oval should be positioned relative to the plasma convection pattern. For the quiet time auroral oval that we adopted, the trough in the dusk section is in a region of predominately eastward flow (see Figures 1 and 2). However, if the auroral oval were contracted by $2^{\circ}$ of latitude, the plasma flow just equatorward of the duskside auroral oval would be westward. To determine the extent to which the uncertainly in the oval position affects our results, we repeated our ion density calculations by keeping all of our ionosphericatmospheric parameters the same, except for the contraction of the auroral oval by $2^{\circ}$ of latitude.

The effect of such a contraction is shown in Figure 10, where contours of the $\mathrm{O}^{+}$density at $300 \mathrm{~km}$ are plotted in the MLT reference frame. For easy comparison, the left panel reproduces the results we presented earlier for our quiet time oval, while the right panel shows the effect of the contracted oval; both panels are for the same UT. The oval region is bounded by the $2.6 \times 10^{5}$ $\mathrm{cm}^{-3}$ contour, while the trough is bounded by the $4 \times 10^{3} \mathrm{~cm}^{-3}$ contour. For the contracted oval the trough extends signifi cantly further into the afternoon sector, 15.5 hours MLT instead of 17.5 hours MLT. This highlights a major difficulty in performing detailed modeling of features such as the trough in that the auroral oval is a region of highly structured precipitation which is known only statistically. The results shown in Figure 10 indicate that statistically allowable variations in the oval boundary have an important effect on the longitudina extent of the main trough. It is therefore not surprising the statistical studies of the location and form of the main trough show a great deal of variability. 

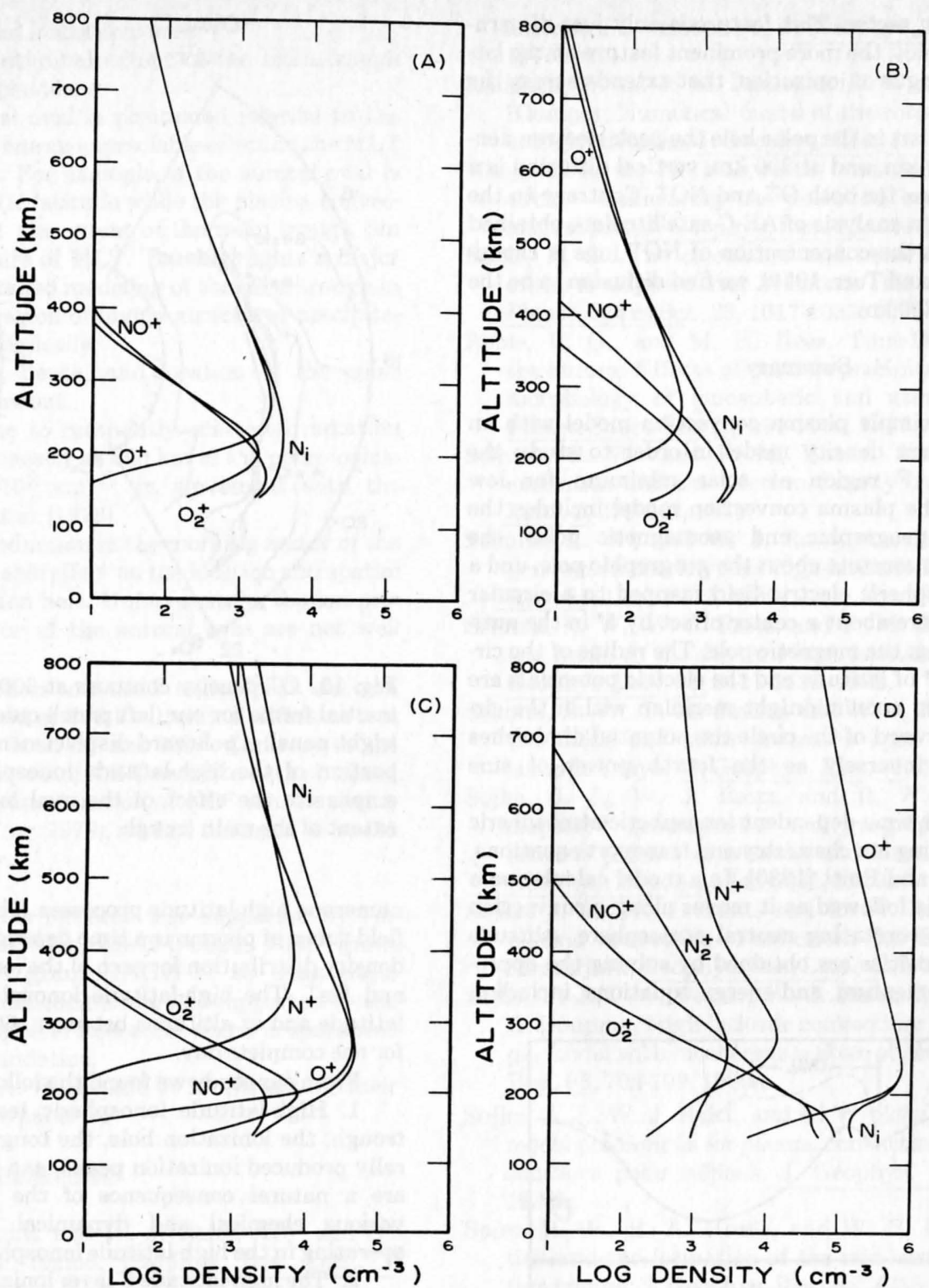

Fig. 8. Representative ion density profiles as a function of altitude. These profiles were selected to show the wide variation in composition that is possible depending on location and universal time. The locations and universal times are (a) the polar hole at 24 UT, (b) the polar hole at 5 UT, (c) in the polar cap adjacent to the oval at local midnight and 12 UT, and (d) in the oval at local midnight and 6 UT.

\section{The Polar Hole}

As had been shown in Plate 1, our model calculations produce a 'polar hole' in F region ionization similar to the one observed by Brinton et al. [1978]. Although a detailed comparison between theoretical predictions and observations of polar hole characteristics was not possible, we did note that our calculated polar hole appeared to be smaller and in a slightly different position from the one measured by Brinton et al. [1978]. $T_{0}$ a large extent the location and size of our polar hole was determined by our auroral oval production rates. However, as was noted earlier, our adopted auroral oval production rates appear to be too large, particularly in the morning sector of the oval.

In order to determine the extent to which auroral production rates influence the size and location of the polar hole, we repeated the calculations that led to Plate 1, except that we set the production rates in the morning sector of the oval to zero. Although this procedure leads to an underestimation of the effect that auroral precipitation has on the location and size of the polar hole, it does provide a contrasting case. In this regard we note that at present there are no models of the gross particle precipitation patterns for the morning sector oval, and therefore, until they become available, accurate detailed modeling of the polar hole characteristics is not possible.

Plate 2 shows the $\mathrm{O}^{+}$density contours at $300 \mathrm{~km}$ for the case of no auroral production in the morning sector of the oval. The comparison of Plates 1 and 2 indicate that our auroral production rates had a significant effect on the size and location of the polar hole. Without morning sector auroral production, the polar hole is considerably larger and it has moved toward midnight into the region adjacent to the oval. This new location of the polar hole corresponds very well with that measured by Brinton et al. [1978].

With regard to the depth of the polar hole, our model calculations produced $\mathrm{O}^{+}$densities as low as $2 \times 10^{2} \mathrm{~cm}^{-3}$, but there was also a significant UT variation. This UT variation can be clearly seen by comparing the two UT plots shown in Plate 2. Not only is there a significant variation in the size and location of the polar hole, but at $0600 \mathrm{UT}$ a region of low $\mathrm{O}^{+}$density 
extends into the noon sector. This feature is only just discernable on the 1800 UT plot; the more prominent feature on the latter plot being the 'tongue of ionization' that extends across the polar cap.

Finally, we note that in the polar hole the peak electron density is well below $300 \mathrm{~km}$, and at $300 \mathrm{~km}$, vertical diffusion is a very important process for both $\mathrm{O}^{+}$and $\mathrm{NO}^{+}$. Contrary to the suggestion based on an analysis of AE-C satellite data obtained in the polar hole that the concentration of $\mathrm{NO}^{+}$ions is chemically controlled (Torr and Torr, 1979), we find diffusion to be the dominant process at $300 \mathrm{~km}$.

\section{Summary}

We combined a simple plasma convection model with an ionospheric-atmospheric density model in order to study the high-latitude winter $F$ region at solar minimum for low magnetic activity. The plasma convection model includes the offset between the geographic and geomagnetic poles, the tendency of plasma to corotate about the geographic pole, and a dawn/dusk magnetospheric electric field mapped to a circular region in the ionosphere about a center offset by $5^{\circ}$ in the antisunward direction from the magnetic pole. The radius of the circle corresponds to $17^{\circ}$ of latitude and the electric potentials are aligned parallel to the noon/midnight meridian within the circular region. Equatorward of the circle the potential diminishes radially and varies inversely as the fourth power of sine magnetic colatitude.

The details of our time dependent ionospheric-atmospheric density model, including ion chemistry and transport equations, are given by Schunk and Raitt [1980]. In a model calculation a field tube of plasma is followed as it moves along a convection trajectory through a corotating neutral atmosphere. Altitude profiles of the ion densities are obtained by solving the appropriate continuity, momentum, and energy equations, including

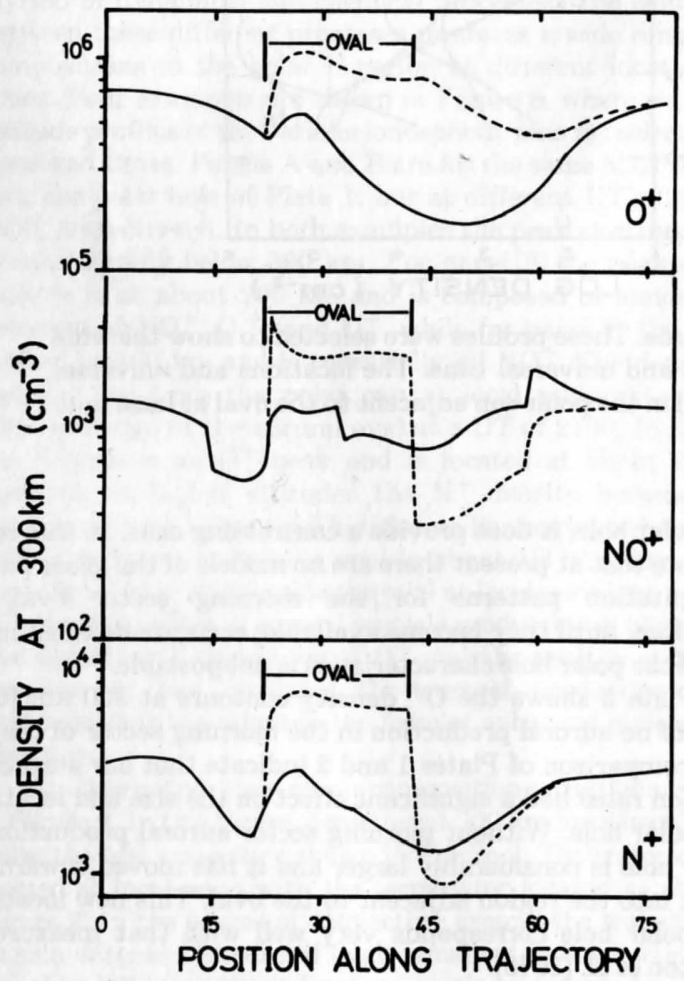

Fig. 9. Variation of selected ion densities at $300 \mathrm{~km}$ along the test plasma trajectory calculated with (dashed curves) and without (solid curves) production due to auroral precipitation. The position along the trajectory is indicated by the number of steps from local noon (see Figure 2). The location of the auroral oval is also shown in the figure.
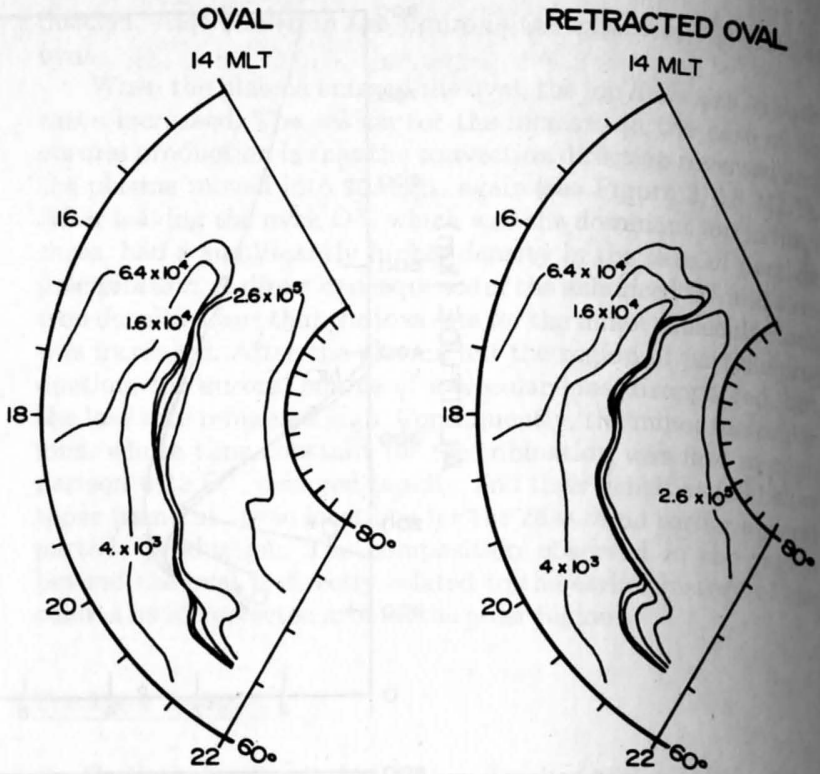

Fig. $10 . \mathrm{O}^{+}$density contours at $300 \mathrm{~km}$ in the magnetic quasiinertial frame for our (left panel) quiet time auroral oval and for (right panel) a poleward displacement of this oval by $2^{\circ}$. Only a portion of the high-latitude ionosphere is shown in order to emphasize the effect of the oval location on the longitudinal extent of the main trough.

numerous high-latitude processes. The result of following many field tubes of plasma is a time dependent, three-dimensional ion density distribution for each of the ions $\mathrm{NO}^{+}, \mathrm{O}_{2}{ }^{+}, \mathrm{N}_{2}{ }^{+}, \mathrm{O}^{+}, \mathrm{N}^{+}$ and $\mathrm{He}^{+}$. The high-latitude ionosphere above $54^{\circ} \mathrm{N}$ magnetic latitude and at altitudes between 160 and $800 \mathrm{~km}$ was covered for one complete day.

From our study we found the following:

1. High-latitude ionospheric features, such as the main trough, the ionization hole, the tongue of ionization, the aurorally produced ionization peaks, and the universal time effects, are a natural consequence of the competition between the various chemical and dynamical processes known to be operating in the high-latitude ionosphere.

2. The high-latitude $\mathbf{F}$ layer ionization exhibits a significant UT variation owing to the displacement between the geomagnetic and geographic poles. The peak electron density at a given location and local time can vary by an order of magnitude due to this UT effect.

3. Some ionospheric processes can be better analyzed in certain reference frames. For example, processes related to solar radiation should be studied in the geographic inertial frame, while the effects of magnetospheric processes should be studied in a magnetic frame. However, because of competition between the various high-latitude processes, neither the geographic inertial frame nor a magnetic frame is completely satisfying.

4. A simulation of an in situ $\mathrm{O}^{+}$density measurement along a $300-\mathrm{km}$ circular satellite orbit that traverses the polar region in the dawn-dusk plane indicates that the interpretation of satellite data obtained at high-latitudes is not always straightforward because of the UT dependence of the ionosphere.

5. Because of the competition between the various dynamical and chemical processes, a wide range of ion compositions can occur in the polar $F$ region at different locations and times. Also, the height of the F region peak electron density displays a significant spatial and temporal variation.

6. The minimum value for the electron density in the main trough is sensitive to nocturnal maintenance processes, such as ion production due to resonantly scattered radiation, ion production due to a small flux of precipitating particles, and a 
neutral wind induced upward ionization drift.

7. The depth and longitudinal extent of the main trough exhibit a significant UT dependence.

8. The way the auroral oval is positioned relative to the plasma convection pattern has an appreciable effect on the MLT extent of the main trough. For example, if the auroral oval is contracted by $2^{\circ}$ of magnetic latitude while the plasma convection pattern remains fixed, the extent of the main trough can change by more than 2 hours of MLT. This highlights a major difficulty in performing detailed modeling of the main trough in that the auroral oval is a region of highly structured precipitation that is known only statistically.

9. The spatial extent, depth, and location of the polar ionization hole are UT dependent.

10. Ion production due to resonantly scattered radiation can maintain the electron density at $300 \mathrm{~km}$ in the polar ionization hole at about $2 \times 10^{2} \mathrm{~cm}^{-3}$, in agreement with the measurements of Brinton et al. [1978].

11. The level of ion production in the morning sector of the auroral oval has an appreciable effect on the location and spatial extent of the polar ionization hole. Unfortunately, the ion production rates in this sector of the auroral oval are not well known at this time.

12. In the polar ionization hole the $\mathbf{F}$ region peak electron density is below $300 \mathrm{~km}$, and at $300 \mathrm{~km}$, vertical diffusion is a very important process for both $\mathrm{O}^{+}$and $\mathrm{NO}^{+}$. Contrary to the suggestion based on an analysis of AE-C satellite data obtained in the polar hole that the concentration of $\mathrm{NO}^{+}$ions is chemically controlled (Torr and Torr, 1979), we find diffusion to be the dominant process at $300 \mathrm{~km}$.

Acknowledgements. This research was supported by Air Force contract USAF/ESD F19628-79-C-0025, NSF grant ATM80-15497, and NASA grant NAGW-77 to Utah State University. The computer modeling effort was supported by the National Center for Atmospheric Research, which is sponsored by the National Science Foundation.

The Editor thanks R. A. Heelis and J. M. Straus for their assistance in evaluating this paper.

\section{References}

Banks, P. M., R. W. Schunk, and W. J. Raitt, $\mathrm{NO}^{+}$and $\mathrm{O}^{+}$ in the high-latitude F region, Geophys. Res. Lett., 1, 239-242, 1974.

Brinton, H. C., J. M. Grebowsky, and L. H. Brace, The highlatitude winter $\mathrm{F}$ region at $300 \mathrm{~km}$ : Thermal plasma observations from AE-C, J. Geophys. Res., 83, 4767-4776, 1978.

Engebretson, M. J., K. Mauersberger, D. C. Kayser, W. E. Potter, and A. O. Nier, Empirical model of atomic nitrogen in the upper thermosphere, J. Geophys. Res., 82, 461-471, 1977.

Feldstein, Y. I., and G. V. Starkov, Dynamics of auroral belt and polar geomagnetic disturbances, Planet. Space Sci., 15, 209-229, 1967.

Knudsen, W. C., Magnetospheric convection and the high- latitude F2 ionosphere, J. Geophys. Res., 79, 1046-1055, 1974.

Knudsen, W. C., P. M. Banks, J. D. Winningham, and D. M. Klumpar, Numerical model of the convecting $\mathrm{F}_{2}$ ionosphere at high latitudes, J. Geophys. Res., 82, 4784, 1977.

Meng, C.-I., R. H. Holzworth, and S.-I. Akasofu, Auroral circle - Delineating the poleward boundary of the quiet auroral belt, J. Geophys. Res., 82, 164-172, 1977.

Roble, R. G., The calculated and observed diurnal variation of the ionosphere over Millstone Hill on 23-24 March 1970, Planet. Space Sci., 23, 1017-1033, 1975.

Roble, R. G., and M. H. Rees, Time-Dependent studies of the aurora: Effects of particle precipitation on the dynamic morphology of ionospheric and atmospheric properties, Planet. Space Sci., 25, 991-1010, 1977.

Schunk, R. W., and P. M. Banks, Auroral $\mathrm{N}_{2}$ vibrational excitation and the electron density trough, Geophys. Res. Lett., 2, 239-242, 1975.

Schunk, R. W., and W. J. Raitt, Atomic nitrogen and oxygen ions in the daytime high-latitude F region, J. Geophys. Res., 85, 1255-1272, 1980.

Schunk, R. W., W. J. Raitt, and P. M. Banks, Effect of electric fields on the daytime high-latitude $\mathrm{E}$ and $\mathrm{F}$ regions, J. Geophys. Res., 80, 3121-3130, 1975.

Schunk, R. W., P. M. Banks, and W. J. Raitt, Effects of electric fields and other processes upon the nighttime highlatitude F layer, J. Geophys. Rès., 81, 3271-3282, 1976.

Sojka, J. J., W. J. Raitt, and R. W. Schunk, Effect of displaced geomagnetic and geographic poles on highlatitude plasma convection and ionospheric depletions, $\mathrm{J}$. Geophys. Res., 84, 5943-5951, 1979a.

Sojka, J. J., W. J. Raitt, and R. W. Schunk, High-latitude plasma convection: Predictions for EISCAT and Sondre Stromfjord, Geophys. Res. Lett., 6, 877-880, 1979b.

Sojka, J. J., J. C. Foster, W. J. Raitt, R. W. Schunk, and J. R. Doupnik, High-latitude convection: Comparison of a simple model with incoherent scatter observations, J. Geophys. Res., 85, 703-709, 1980a.

Sojka, J. J., W. J. Raitt, and R. W. Schunk, A comparison of model predictions for plasma convection in the northern and southern polar regions, J. Geophys. Res., 85, 1762-1768, $1980 \mathrm{~b}$.

Spiro, R. W., R. A. Heelis, and W. B. Hanson, Ion convection and the formation of the mid-latitude $\mathrm{F}$ region ionization trough, J. Geophys. Res., 83, 4255-4264, 1978.

Torr, M. R., and D. G. Torr, Recombination of $\mathrm{NO}^{+}$in the mid-latitude trough and the polar ionization hole, J. Geophys. Res., 84, 4316-4320, 1979.

Volland, H., A model of the magnetospheric electric convection field, J. Geophys. Res., 83, 2695-2699, 1978.

Watkins, B. J., A numerical computer investigation of the polar F region ionosphere, Planet. Space Sci., 26, 559-569, 1978.

(Received August 4, 1980;

revised October 10, 1980;

accepted October 13, 1980.) 